\title{
Personality Organization Diagnostic Form
}

Diguer, Normandin \& Hébert

Laboratoire de recherche en personnalité et psychopathologie, Université Laval. @ 2001

Subject:

Evaluator:

Date:

Material used for evaluation:

Instructions: Score all items according to the typical subject's psychological functioning. See the PODF manual for scoring (Diguer et al

2006) for detailed guidelines. The SCID questions are given as examples; this measure is only one possible source of data for PODF scoring.

1. Identity diffusion / Identity integration

1.1. Subjective experience of the Feeling of emptiness

Secure self identity

self. SCID-II, question \# 100.

$\begin{array}{ccccccc}\square & \square & \square & \square & \square & \square & \square \\ -3 & -2 & -1 & 0 & 1 & 2 & 3\end{array}$

1.2. Self perceptions. SCID-II, questions Contradictory \# 71, 92, 93, 94, 95, 99.

\begin{tabular}{ccccccc}
$\square$ & $\square$ & $\square$ & $\square$ & $\square$ & $\square$ & $\square$ \\
-3 & -2 & -1 & 0 & 1 & 2 & 3 \\
\hline
\end{tabular}

1.3. Subjective experience of the

Discontinuity

Continuity self in time.

\begin{tabular}{ccccccc}
$\square$ & $\square$ & $\square$ & $\square$ & $\square$ & $\square$ & $\square$ \\
-3 & -2 & -1 & 0 & 1 & 2 & 3 \\
\hline
\end{tabular}

1.4 Behavior-emotions integration. No integration

Good integration SCID-II, questions \# 96, 97, 98, 101,

102, 122, 123, 124. SCID-I, questions

\# 33 to 40,45 to 48.

$\begin{array}{ccccccc}\square & \square & \square & \square & \square & \square & \square \\ -3 & -2 & -1 & 0 & 1 & 2 & 3\end{array}$

1.5 Object perceptions. SCID-II, questions \# 91.

Contradictory

Integrated

$\square$

$-3$

$-2$

$-1$

Shallow, flat

Empathy

1.6 Perceptions of others.

$\begin{array}{ccccccc}\square & \square & \square & \square & \square & \square & \square \\ -3 & -2 & -1 & 0 & 1 & 2 & 3\end{array}$

Total Identity Score 


\section{Defense Mechanisms.}

\subsection{Primitive Defense Mechanisms.}

Absence Rare Moderate Frequent 0 1 2

2.1.1 Denial (borderline and psychotic) :

$\square$ memory of perceptions, thoughts or feeling about splitted parts of self or others without emotional relevance and / or

$\square$ lack of concern, anxiety or emotional reaction about

serious or pressing need, conflict or danger. SCID-II, questions \# 96, 98.

2.1.2 Splitting :

$\square$ division of others into all go and all bad and / or

$\square$ sudden and complete reversal of feelings and

conceptualizations. SCID-II, questions \# 45, 46, 71, 91, 99, 103

2.1.3 Omnipotence (primitive idealization):

$\square$ Self representations. SCID-II, questions \# 27, 73-81, 83, 84, 88, 89 and / or

$\square$ object representations

2.1.4 Omnipotent control :

$\square$ by the Self. SCID-II, questions \# 82, 120, 121 and / or

$\square$ by the object

2.1.5 Primitive devaluation :

$\square$ Self devaluation and self destruction. SCID-II, questions \# 6, 12, 34, 35, 97, 98 and / or

$\square$ Object devaluation. SCID-II, questions \# 29, 37, 38, 89.

Total Primitive Defense Mechanism Score

$/ 15$

2.2 Mature Defense Mechanisms

Absence Rare Moderate Frequent

2.2.1 Idealization

2.2.2 Devaluation

2.2.3 Isolation

2.2.4 Rationalization and/or intellectualisation

2.2.5 Denegation and/or suppression

Total Mature Defense Mechanism Score 
3. Reality Testing.

\begin{tabular}{cccc|} 
Absence & Rare & Moderate & Frequent \\
0 & 1 & 2 & 3
\end{tabular}

3.1 Lack of differentiation between self and others. SCID-I, questions \# 50, 55, 56, 57, 58.

3.2 Failure to differentiate intrapsychic from external origin of perceptions and stimuli

(hallucinations or delusions). SCID-I, questions \# 59-62. SCID-II, questions \# 55, 56, 57.

3.3 Lack of the capacity to evaluate realistically one's own affect, behavior and thought content in terms of social norms. SCID-II, questions \# 64.

3.4 Presence of grossly inappropriate or bizarre affects, thought contents or behaviors. SCID-II, criteria 4, criteria 7.

Total Reality Testing Score

\section{Quality of Object Relations}

Score the typical object relations in the right column. If possible, also indicate the main subtype (for example Paranoid in the Low Borderline).

\begin{tabular}{|c|c|c|}
\hline 1 & Symbiotic with fear of disintegration and annihilation & $\square$ \\
\hline $2 a$ & $\begin{array}{c}\text { Low Borderline Organization with fear of the object } \\
\square \text { Paranoid } \square \text { Schizoid }\end{array}$ & $\square$ \\
\hline $2 b$ & $\begin{array}{c}\text { Low Borderline Organization with control of the object } \\
\square \text { Malignant narcissism } \square \text { Antisocial }\end{array}$ & $\square$ \\
\hline 2c & $\begin{array}{cc}\text { High Borderline Organization with fear of abandonment } \\
\square \text { Dependant } & \square \text { Histrionic } \\
\square \text { Sado-masochistic } & \square \text { Narcissism } \quad \square \text { Borderline }\end{array}$ & $\square$ \\
\hline 3 & $\begin{array}{c}\text { Edipal with fear of castration - depression } \\
\square \text { Hysteria } \\
\square \text { Obsessive-compulsive } \\
\text { Depressive masochistic }\end{array}$ & $\square$ \\
\hline
\end{tabular}

\section{Global Personality Organization (GPO) Diagnosis and Dimensions}

For each dimension, circle the characteristic that best describes subject's functioning; then according to guidelines below, identify GPO.

\begin{tabular}{|c|c|c|c|c|}
\hline GPO & \multicolumn{3}{|c|}{ Dimensions } \\
\hline NPO, BPO or & Identity: & Defenses: & Object \\
PPO & Diffusion or Integration & Primitive or Mature & $\begin{array}{c}\text { Reality Testing: } \\
\text { Lack or Good }\end{array}$ & $\begin{array}{c}\text { Relations: } \\
1,2 a, 2 b, \\
2 c, 3\end{array}$ \\
\hline
\end{tabular}

Reminder of the guidelines for GPO Diagnosis

\begin{tabular}{|l|c|c|c|c|}
\hline \multirow{2}{*}{ GPO } & \multicolumn{4}{|c|}{ Dimensions } \\
\hline & Identity & Defenses & Reality Testing & Type of Object Relations \\
\hline Neurotic & Integrated & Mostly mature & Good & Oedipal \\
\hline Borderline & Diffused & Mostly primitive & Mostly good & Borderline: $2 \mathrm{a}, 2 \mathrm{~b}$ or $2 \mathrm{c}$ \\
\hline Psychotic & Diffused & Mostly primitive & Impaired & Psychotic \\
\hline
\end{tabular}

